Cathy Atkinson* ${ }_{a}$, Sandra Dunsmuir ${ }_{b}$, Jane Lang ${ }_{b}$, \& Sarah Wright $c$

Developing a competency framework for the initial training of educational psychologists working with young people aged $16-25$

a. Room A6.5, Ellen Wilkinson Building, University of Manchester, Oxford Road, Manchester, MI3 9PL, 016127535 II, cathy.atkinson@manchester.ac.uk

b. Doctorate in Educational and Child Psychology, Educational Psychology Group, University College London, 26 Bedford Way, London WCIH OAP. Tel: 0207679 5307. Emails: s.dunsmuir@ucl.ac.uk and langovi@talktalk.net

c. University of Southampton, Doctorate in Educational Psychology, Building 44a, Highfield Campus, SO17 1BJ. Email: $\underline{\text { S.F.Wright@soton.ac.uk }}$

\footnotetext{
* corresponding author
} 


\title{
Developing a competency framework for the initial training of educational psychologists working with young people aged 16-25
}

\begin{abstract}
The Children and Families Act (2014) extends statutory protections for young people with Special Educational Needs and Disabilities until age 25. Consequently the core curriculum for trainee educational psychologists (TEPs) needs to be developed beyond the current focus of work with early years and school-age children. In order to define requisite professional competencies for working with young people aged 16-25 with learning difficulties and disabilities and mental health needs, the Delphi Technique was employed to obtain consensus amongst an expert reference group. Two rounds of an online questionnaire and a face-to-face meeting with educational psychologists (EPs) reporting expertise in working with post 16 learners enabled the identification of areas to be added to or extended within existing training curricula. A competency framework for EPs working with young people aged 16-25 is proposed and implications for both TEPs and practitioner educational psychologists (EPs) explored.
\end{abstract}

Key words: young people, transition, adulthood, person-centred approaches, Code of Practice 


\section{Introduction}

\section{The legislative context and the role of EPS}

In March 2014, the UK Children and Families Act received Royal Assent, offering new legislation for children and young people with special education needs which extends provision from birth, up to the age of 25. From September 2014, Education, Health and Care (EHC) Plans replaced the previous system of statements of special education needs (SEN) under the new Code of Practice (Department for Education (DfE), 2014), extending statutory protections into adulthood. The extension of the role of EPs in working with young people up to the age of 25 represents one of the most significant developments the profession has ever experienced. Furthermore, post-16 it is intended that professionals should engage directly with young people, rather than services being commissioned via a third party, enabling young people to be integral to the planning process. The DfE funded Preparing for Adulthood (2013) programme represents the strand of the SEN reforms which focus on the needs of young people aged 14-25, and this advocates improved choices and control for disabled young people as they move towards adulthood. The new legal framework proposed by the Children and Families Act (2014) includes EHC plans; the option of a personal budget to support EHC plans; and the requirement to publish a Local Offer of services available to young people up to the age of 25 (DfE, 2014; Preparing for Adulthood, 2013). These are changes to which the profession needs to make a swift response in order to suitably equip EPs and to allow them to feel confident and efficacious in working with young adults.

Although work with young adults represents new territory, Hayton (2009) notes the EPs are uniquely positioned to support young adults to develop personal skills which they can carry beyond the classroom, including improving self-awareness, promoting a positive sense of identity, identifying strengths and skills and raising aspirations. She notes that these skills may be particularly important in preparing for transition to post-compulsory education and into vocational settings and identifies a key role for EPs in working collaboratively with schools, careers services and other agencies in supporting the transition of young people into adult life. 
Specifically, Preparing for Adulthood (2013) identifies four outcomes, devised following consultation with young people which should be addressed in preparing for adulthood. These are:

1. Paid employment

2. Good health

3. Independent living

4. Community inclusion

Furthermore five elements identified as important to improving life chances for disabled young people are also highlighted (Preparing for Adulthood, 2013). These are:

1. Develop a shared vision

2. Raise aspirations

3. Personalise your approach

4. Improve post-16 options and support

5. Plan services together

These notions are congruent with research findings detailing the importance of young people's involvement in decisions about their future (Carter, Cameron, Houghton, \& Walton, 2013); and the role of self-determination in improving post-school outcomes (Shogren, Wehmeyer, Palmer, Rifenbark, \& Little, 2013). This is important even where a young person may have complex communication, learning or emotional needs which makes it more difficult for them to express opinions and make decisions. The Mental Capacity Act (2005) starts from the assumption that an adult aged 16 or over has the full legal capacity to make decisions for themselves (the right to autonomy) unless it can be shown that they lack the capacity to make a decision at the time it needs to be made (The Stationery Office (TSO), 2005). Furthermore enabling and supporting people to express their opinions is central to the ethos of the Mental Capacity Act (2005) and it states that "before deciding that someone lacks the capacity to make a particular decision, it is important to take all practical and appropriate steps to enable them to make that decision themselves" (TSO, 2005, p.29). The SEN Code of Practice (DfE, 2014) advocates a person-centred planning approach for harnessing the needs, wishes and goals of young people. This is significant for EP practice, 
where there has been a longstanding interest in ascertaining the 'Voice of the Child' (for more recent examples see Hammond, 2013; Ingram, 2013), including those with the most severe and complex needs (Harding, 2009).

\section{Development of Post-School Practice}

The development of Scottish Post-School Psychological Services (PSPS) provides a potentially useful model for services in other parts of the UK, with a range of post-school practice documented in a special edition of Educational and Child Psychology (Mackay \& Hellier, 2009). Because of the provision of PSPS funding by the Scottish Government, following the Beattie Report (Scottish Executive, 1999), Scotland has had the opportunity to grapple with the issues and dilemmas associated with work in this area, while internationally educational psychology practice predominantly remains within the sphere of 0-19 provision (MacKay, 2009).

While within the Scottish sector, there has been considerable diversity in the provision of PSPS, there are common characteristics of good practice, including working collaboratively within a multiagency context and seeking to make connections with new partners. The effectiveness of support around transitions is also considered to be a key indicator of successful collaboration. The development of PSPS has also reportedly encouraged psychological services to work in clusters, that have promoted shared models of post-school good practice (Hellier, 2009). MacKay and Hellier (2009) highlight the need to connect with adult services and identify implications for training, staffing and service organisation and delivery, while Cerebra (2014) identify the changing responsibilities of education, social and health services as young people make the transition to adulthood, noting how support and access criteria vary between child and adult services. It is interesting that in Scotland, development of PSPS has reportedly enabled greater flexibility surrounding the EP role (MacKay, 2009).

Although a contemporary area of practice, there is growing interest in how EPs can work to support post-16 learners. This includes identifying and supporting young people who are not in education, employment or training (NEET) (Arnold \& Baker, 2012; Currie \& Goodall, 2009); post school transitions (Bradley, 2012; Craig, 2009; Knox, 2011; Mallinson, 2009); 
supporting the development of young people's sexuality (Robinson, 2010) and working with young people at risk of social exclusion (Jane, 2010).

\section{Developing Competencies within the Context of Initial Educational Psychology Training}

Evans, Grahamslaw, Henson and Prince (2012) explored views held by principal educational psychologists (PEPs) and recently qualified educational psychologists (RQEPs) about the level to which initial professional training was 'fit for purpose'. Whilst this research predates legislative changes that have extended the role of the EP to working with the 19-25 age range, it is significant that one of the key findings from the study was that initial training should prepare trainees for a changing EP role and working climate. In a similar vein, Fallon, Woods, \& Rooney (2010) describe how consistent "reconstruction", "reformulation" and "refocussing" has led to a lack of confidence about professional identity in light of the multiple socio-legislative challenges which have impacted on the role of the EP. The authors suggest that "EPs need to emerge from initial professional training being able to articulate a coherent view of their psychological skills set, as well as a clear view of the context within which this can be applied for the benefit of [children and young people]" (p.15) and call for greater clarity and prominence of a core-curriculum for initial training.

This study describes a project funded by the Higher Educational Academy (HEA) and led by the second author, involving Programme Directors on the initial doctoral training programmes for EPs at University College London, University of Manchester and University of Southampton. The aim was to develop a comprehensive and evidence-led framework to assess professional skills, competence and performance in educational psychology. The first phase of the HEA project involved developing a curriculum for educational psychology training, by identifying key competencies required for work with young people aged up to 25 years, their families and educators in the settings in which they live and learn. This involved consultation with expert educational psychologists in order to define relevant professional competencies required for this area of work, in terms of knowledge, performance and action (Miller, 1990). 


\section{Obtaining Consensus on Curriculum Content}

The Delphi Technique is a method of establishing consensus in a group without bringing its members together for a meeting. It is a structured communication technique relying on a panel of experts, originally developed by the Rand cooperation to forecast the impact of technology on warfare (Dalkey, 1969). Linstone and Turoff (2002) state that in order to accomplish this structured communication "there is provided some feedback of individual contributions of information and knowledge, some assessment of the group judgement or view, some opportunity for individuals to revise views and some degree of anonymity for the individual responses" (p. 3). A key element of the approach is the revision of perspective in the light of views expressed by other group members. Its underlying premise is that the product of group consensus is more useful than the underpinning individual views.

The basic method is very simple. Typically, a group of experts answer questionnaires in two or more rounds. After each round, the facilitator provides an anonymous summary of the experts' view. Individual experts are then provided with information which allows them to compare their own responses with collated responses and are encouraged to revise their responses in the light of this new information. This iterative process continues until group consensus is achieved. This is usually on the basis of some pre-determined stop criterion (e.g. number of rounds; stability of results; a specified level of consensus). The success of a Delphi study rests on following this iterative cycle, and on the combined expertise of the participants who make up the panel.

\section{Delphi Poll Phase One}

Given the relationship between initial training curricula and professional practice experience it was paramount that key stakeholders were directly involved in the derivation of the competency framework. To this effect, volunteer participant EPs with 'expertise in working with 16-25 year olds' were sought via a posting on EPNET, the main professional electronic discussion forum for UK based EPs. Respondents were asked to provide a couple of sentences to describe their experience and knowledge in working with the 16-25 population. The self-selecting sample $(n=28)$ which represented a geographical spread of 
EPs across England and Wales, was invited to participate in the research by responding to an initial questionnaire delivered by online survey (Opinio). The first survey set out the following six questions to which respondents provided their ideas about potential curriculum content:

1. What aspects of the Context in which young people aged 16-25 live, learn and work should be included in the training curriculum for educational psychologists?

2. What aspects of Legislation and policy should be included in the training curriculum for educational psychologists?

3. What aspects of Assessment should be included in the training curriculum for educational psychologists?

4. What aspects of Interventions and Outcomes should be included in the training curriculum for educational psychologists?

5. What aspects of Development should be included in the training curriculum for educational psychologists?

6. What aspects of Transition should be included in the training curriculum for educational psychologists?

Participants were invited to rate the importance of three proposed curriculum topics on a five point Likert scale with response options ranging from extremely important to extremely unimportant. These were developed by the project team, via consultation with a local EP expert in 16-25 practice. Respondents were also given an opportunity to provide qualitative statements to justify their proposals.

The proposed curriculum topics are shown in Table 1 below:

Table 1: Curriculum topics proposed at phase one of the Delphi questionnaire

\begin{tabular}{|l|l|}
\hline Curriculum area & Exemplar themes \\
\hline 1. Context & $\begin{array}{l}\text { - Curriculum in Further Education } \\
\text { - Professional roles and responsibilities }\end{array}$ \\
\hline 2. Legislation and policy & $\begin{array}{l}\text { - Funding mechanisms } \\
\end{array}$ \\
& $\begin{array}{l}\text { - Mental Capacity Act (2005) } \\
\text { (2010) Act (2009) and Autism Strategy }\end{array}$ \\
\hline
\end{tabular}




\begin{tabular}{|c|c|}
\hline & - Disabled Students Allowances (DSA). \\
\hline 3. Assessment & $\begin{array}{l}\text { - Psychometric assessment (specialised } \\
\text { instruments) } \\
\text { - Functional assessment } \\
\text { - } \text { Assessment focus (dyslexia) }\end{array}$ \\
\hline 4. Intervention and Outcomes & $\begin{array}{l}\text { - Study skills } \\
\text { - Therapeutic interventions e.g. CBT } \\
\text { - Life skill development }\end{array}$ \\
\hline 5. Development & $\begin{array}{l}\text { - Neurological development } \\
\text { - Sexuality } \\
\text { - } \text { Mental health }\end{array}$ \\
\hline 6. Transition & $\begin{array}{l}\text { - Transition to FE } \\
\text { - Transition to employment } \\
\text { - Transition to independent/community } \\
\text { living }\end{array}$ \\
\hline
\end{tabular}

ParticipantsOf the twenty-eight EPs sent the initial online questionnaire, 24 replied within the specified timescales. Of these, $50.1 \%$ were employed as Local Authority (LA) EPs, with $25.0 \%$ maingrade, $20.9 \%$ senior and $4.2 \%$ principal EPs being represented in the sample. EPs in private practice represented $41.7 \%$, with $8.4 \%$ being employed in other settings (e.g. university tutor). Two thirds of the sample were female, with $91.7 \%$ identifying themselves as White British. All of the respondents had more than six years' experience as an EP, with two thirds of respondents reporting more than 15 years of EP practice.

Phase One ResultsAll responses were summarised quantitatively. In relation to the proposed curriculum topics, participants were given feedback about their own responses, in relation to responses provided by the wider sample (see Table 2 below). All additional free responses were analysed and aggregated by two members of the project team using content analysis. This yielded the following additional themes within each category (Table 3). 
Table 2: Individual and aggregated responses to Phase I proposed curriculum topics

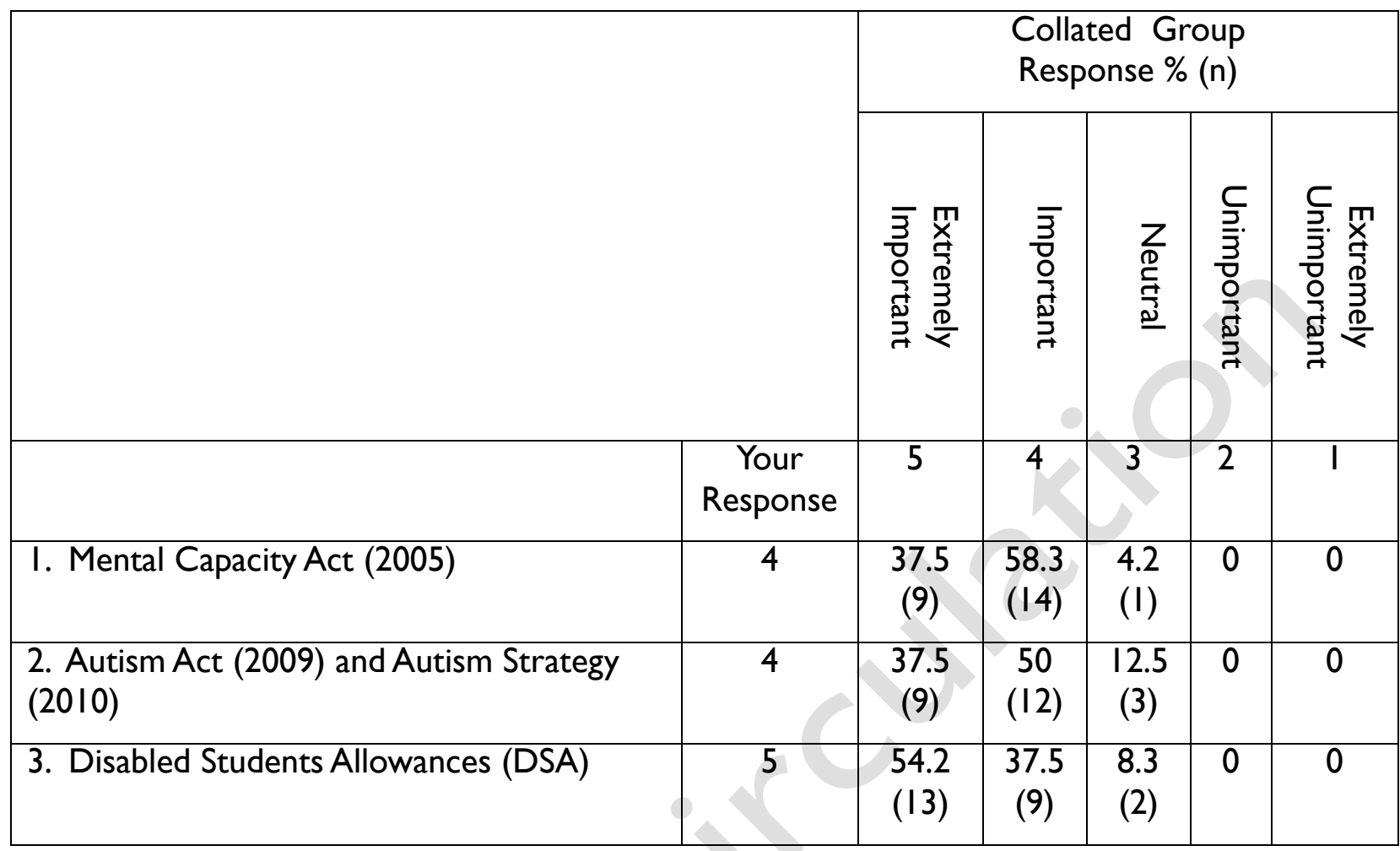

Table 3: Themes arising from Phase I content analysis

\begin{tabular}{|l|l|}
\hline Category & Themes \\
\hline Context & $\begin{array}{l}\text { Employment; preparation and skill; multi-agency working; access to } \\
\text { post-16 services (LA and voluntary sector); commissioning services/LA } \\
\text { provision; Further Education (FE) and Higher Education (HE) priorities, } \\
\text { pressures and curriculum; working with organisations; alternatives to } \\
\text { FE/NEET; families: culture, interdependence and impact; health and } \\
\text { social care; criminal justice system }\end{array}$ \\
\hline $\begin{array}{ll}\text { Legislation and } \\
\text { policy }\end{array}$ & $\begin{array}{l}\text { Equality Act (20I0); Children and Families Bills, EHC plans and tribunals; } \\
\text { disability legislation (e.g. Carers and Disabled Children Act, 2000); } \\
\text { Learning and Skills Act (2000); Children and Leaving Care Act (2000); } \\
\text { Mental Health Act (2005); consent and decision making - good practice } \\
\text { guidance; guidance on safeguarding and sexual exploitation; Rose Report } \\
\text { (Rose, 2009) }\end{array}$ \\
\hline Assessment & $\begin{array}{l}\text { Specific/general learning difficulties, dyscalculia, autistic spectrum } \\
\text { conditions (ASC), dyspraxia, profound and multiple learning difficulties } \\
\text { (PMLD), complex learning difficulties and disabilities (CLDD); mental } \\
\text { health; adaptive behaviour assessments; dynamic assessment; assessment } \\
\text { purpose and educational progress; client voice/young person's } \\
\text { perspective; consultation and observation; assessing resilience; }\end{array}$ \\
\hline
\end{tabular}




\begin{tabular}{|l|l|}
\hline $\begin{array}{l}\text { Intervention } \\
\text { and outcomes }\end{array}$ & $\begin{array}{l}\text { Person-centred planning; coaching; goal-based outcome measurement; } \\
\text { use of technology to support learning and independence; life skill } \\
\text { development; behaviour, social and emotional (including motivation); } \\
\text { basic skills (reading and numeracy); systemic interventions and strategic } \\
\text { planning }\end{array}$ \\
\hline Development & $\begin{array}{l}\text { Drug and alcohol use; developing independence; cognitive and } \\
\text { neuropsychological development; theories of adult learning; parenting } \\
\text { skills; social and emotional development; vocational skills }\end{array}$ \\
\hline Transition & $\begin{array}{l}\text { Transition to HE; transition to other provisions; transition to } \\
\text { parenthood; transition to adulthood; professional roles and } \\
\text { responsibilities; early identification of those at risk of poor transition or } \\
\text { atypical transition }\end{array}$ \\
\hline
\end{tabular}

Participants were then emailed a summary of:

- Quantitative group results, which included a collation of all items generated under the six categories listed above, and descriptive data summarising the overall importance ratings associated with each one.

- The participant's own response to highlight their individual position in relation to collated group responses.

- Qualitative comments.

\section{Delphi Poll Phase Two}

Participants were asked to read through their individual report and consider their views in light of this new information in a second round of Delphi polling. This time, they were asked to rate whether each item was:

1. Essential within new training curricula for EPs working with young people aged $16-25$ years.

2. Captured in existing 0-19 curricula, but needing extension to address the needs of this older population.

3. Not relevant within the existing role of an EP, or the new extended role. 
The respondent sample $(n=24)$ was identical to that of phase one. Delphi methodology stipulates that the process should be repeated until an appropriate level of consensus has been achieved. Hasson, Keeney and McKenna (2000) recommend that the minimum level of consensus should be $70 \%$. After the second round of Delphi polling there was over $95 \%$ agreement on items that were seen as essential in a new training curriculum and those that were perceived as already being covered in existing curricula.

Within the scope of this paper, it is not feasible to publish the results in full, although these are available via the project website (OSPA Project, 2013). Table 4 below shows details of curriculum topics rated as 'essential in new training curricula for EPs working with YP aged $16-25$ years' by more than $55 \%$ of the respondent sample.

Table 4: Results from Delphi Poll phase 2

\section{Curriculum area}

1. Context

Funding mechanisms

FE and HE priorities, pressures and curriculum

Curriculum in FE

Access to post 16 services (LA and voluntary sector

Alternatives for FE/NEET

Understanding roles and responsibilities of key

professionals
Percentage of respondents

rating topic as essential

\section{Legislation}

Mental Capacity Act (2005)

$70.83 \%$

Disabled Students' Allowance (DSA)

$83.33 \%$

$70.83 \%$

$69.57 \%$

$62.5 \%$

$62.5 \%$

Consent and decision making - good practice

$66.67 \%$

guidance

$58.33 \%$

\section{Assessment}

Mental health

$66.67 \%$

4. Intervention and outcomes

Person-centred planning

$60.87 \%$

Life skill development

$56.52 \%$

\section{Development}

Theories of adult learning

Developing independence 


\section{Transition}

Transition to independent/ community living

$87.5 \%$

Transition to employment

$79.17 \%$

Transition to adulthood

Professional roles and responsibilities at transition

$65.22 \%$

Transition to parenthood

$62.5 \%$

Transition to other provisions

$60.87 \%$

Early identification of those at risk of poor or

$58.33 \%$

atypical transition

Transition to FE

$58.33 \%$

Transition to $\mathrm{HE}$

$58.33 \%$

\section{Delphi Poll Phase Three}

Following examination of the data, it was proposed that curriculum topics rated as 'essential' by more than $65 \%$ of respondents should be included in new training curricula. Those rated as essential by between 55 and $65 \%$ of the sample were prioritised for further consultation with a purposive sample of eight EPs which was selected from the 24 expert participants and invited to attend a meeting. Participants were also asked to debate any areas of high and low agreement, and once this was achieved to provide further information about the individual curriculum areas. As Hasson et al. (2000) argue "the Delphi has been criticized, as it is perceived to force consensus and is weakened by not allowing participants to discuss the issues raised" (p. 1013). By allowing the participants to elaborate on their views it was intended that we would be able to ensure that there was a common understanding of the core components of the new proposed curriculum.

Discussions amongst the expert group also helped to identify essential new curriculum areas which impacted on other categories. Specifically, it was noted that there may be additional responsibilities within 'Assessment' for EPs to make judgements about capacity to learn, or to offer diagnoses in relation to specific learning difficulties observed in adulthood within $\mathrm{HE}$ or FE. After the meeting, a draft curriculum was circulated to the expert group for member checking, providing individuals with the opportunity to comment on, add to or amend the details accordingly. From this document, competencies were developed, based on previous 
models of competency benchmarks for psychologists (Fouad et al., 2009; National Association of School Psychologists, 2010).

\section{Professional competence and fitness to practice}

The competency framework devised from the research is presented in Figure 1 below. It is based on ideas presented by Kaslow et al., (2004), that competencies consist of discrete knowledge, skills, and attitudes. Involving key stakeholders (practising educational psychologists, service managers, university tutors) was important in establishing both foundational competencies (those relating to the core functions of EP practice, such as ethical frameworks and professional standards); and functional competencies which allow competencies to be defined in terms of observable behaviours (Rodolfa et al., 2005). The curriculum for TEPs to work with 16-25 year olds has been devised specifically to develop functional competencies and contains three elements:

\begin{tabular}{|c|l|}
\hline 1. & New knowledge required for working with 16-25 year olds \\
\hline 2. & $\begin{array}{l}\text { Process skills required to deliver psychological services in relation to 16-25 year } \\
\text { olds }\end{array}$ \\
\hline 3. & Existing knowledge that needs extension to work with 16-25 year olds \\
\hline
\end{tabular}

\section{Section 1 - CONTEXT}

\begin{tabular}{|c|c|}
\hline $1.1 \mathrm{a}$ & $\begin{array}{l}\text { Demonstrates knowledge about the types of curricula, courses, programmes and } \\
\text { pathways available to young people aged } 16-25 \text {. }\end{array}$ \\
\hline $1.1 b$ & Understands roles of key professionals in supporting young people aged 16-25. \\
\hline $1 c$ & $\begin{array}{l}\text { Demonstrates awareness of how educational psychologists can support young } \\
\text { people aged } 16-25 \text { in achieving outcomes (including employment, health, community } \\
\text { inclusion and independent living). }\end{array}$ \\
\hline $.1 d$ & $\begin{array}{l}\text { Understands the socio-political context and pressures faced by young people aged } \\
16-25 \text { accessing FE and HE including social and learning issues; mental health issues. }\end{array}$ \\
\hline & $\begin{array}{l}\text { Understands systems, services and resources to support young people aged 16-25, } \\
\text { including Educational, Health and Social Care and Criminal Justice Systems. }\end{array}$ \\
\hline
\end{tabular}




\begin{tabular}{|c|c|}
\hline $1.2 \mathrm{a}$ & $\begin{array}{l}\text { Verbal and non-verbal communications that are appropriate to the professional } \\
\text { context, including in challenging interactions. }\end{array}$ \\
\hline $1.2 b$ & $\begin{array}{l}\text { Respectful of beliefs and values of colleagues within other professional sectors, even } \\
\text { when inconsistent with personal values and beliefs. }\end{array}$ \\
\hline $1.2 d$ & $\begin{array}{l}\text { Working knowledge of multiple and differing world views, professional standards and } \\
\text { contributions across different professional roles, contexts and systems. } \\
\text { Appreciates and integrates perspectives from multiple professions. }\end{array}$ \\
\hline 1.3 & $\begin{array}{l}\text { Other areas to be addressed via an extension to existing curricula: Commissioning of } \\
\text { services and provision mapping for 16-25 year olds; Working with families - } \\
\text { understanding cultural differences in expectations of adulthood and issues of } \\
\text { interdependence between young adults and parents }\end{array}$ \\
\hline
\end{tabular}

\section{Section 2 - LEGISLATION}

\begin{tabular}{|l|l|}
\hline 2.1 & $\begin{array}{l}\text { Demonstrates awareness of key legislation relating to the needs of young people } \\
\text { aged 16-25, including the Mental Capacity Act (2005) and Disabled Students } \\
\text { Allowance (DSA). }\end{array}$ \\
\hline 2.2 & $\begin{array}{l}\text { Spontaneously and reliably identifies complex ethical and legal issues, analyses them } \\
\text { accurately and proactively addresses them. }\end{array}$ \\
\hline 2.3 & $\begin{array}{l}\text { Other areas to be addressed via an extension to existing curricula: Knowledge of } \\
\text { legislation such as the Autism Act (2009) and Autism Strategy (2010); Equality Act } \\
\text { (2010); Children and Families Bills, EHC plans and tribunals; disability legislation (e.g. } \\
\text { Carers and Disabled Children Act, 2000); Learning and Skills Act (2000); Children and } \\
\text { Leaving Care Act (2000); Mental Health Act; consent and decision making - good } \\
\text { practice guidance; guidance on safeguarding and sexual exploitation; Rose Review } \\
\text { (2009); Valuing People (2010). }\end{array}$ \\
\hline
\end{tabular}

\section{Section 3 - ASSESSMENT}

\begin{tabular}{|l|l|}
\hline $3.1 \mathrm{a}$ & $\begin{array}{l}\text { Able to select and use a broad range of psychological assessment methods, } \\
\text { appropriate to the young person, environment and the type of intervention likely to } \\
\text { be required. }\end{array}$ \\
3.1b & $\begin{array}{l}\text { Demonstrates awareness of appropriate methods and protocols for assessing the } \\
\text { mental health of young people aged 16-25. }\end{array}$ \\
\hline $3.1 \mathrm{c}$ & $\begin{array}{l}\text { Understands additional responsibilities which may arise within the context of } \\
\text { assessing post } 16 \text { learners (e.g. capacity to learn; diagnosis of a specific learning } \\
\text { difficulty). }\end{array}$ \\
\hline $\begin{array}{l}\text { Selection of assessment tools reflects a flexible approach to exploring hypotheses } \\
\text { about the needs of the young person in relation to achieving outcomes (including } \\
\text { employment, health, community inclusion and independent living). }\end{array}$
\end{tabular}


3.3 $\quad$ Other areas to be addressed via an extension to existing curricula: Specific/general learning difficulties, dyscalculia, ASC, dyspraxia, PMLD, CCLD; mental health; adaptive behaviour assessments; dynamic assessment; client voice/young person's

perspective; consultation and observation; assessing resilience; vulnerability and risk

\section{Section 4 - INTERVENTIONS AND OUTCOMES}

\begin{tabular}{|c|c|}
\hline $4.1 a$ & $\begin{array}{l}\text { Understands the principles of consent and shared decision making, including the } \\
\text { Mental Capacity Act (2005). }\end{array}$ \\
\hline $4.1 b$ & Understands the principles of person-centred planning. \\
\hline 4.1c & $\begin{array}{l}\text { Demonstrates awareness of how interventions should support young people in } \\
\text { achieving outcomes (including employment, health, community inclusion and } \\
\text { independent living). }\end{array}$ \\
\hline $4.2 \mathrm{a}$ & $\begin{array}{l}\text { Acts in the best interest of the young person and maintains a professional duty of } \\
\text { care. }\end{array}$ \\
\hline $4.2 b$ & Communicates clearly and effectively with clients. \\
\hline 4.3 & $\begin{array}{l}\text { Other areas to be addressed via an extension to existing curricula: coaching; goal- } \\
\text { based outcome measurement; use of technology to support learning and } \\
\text { independence; life skill development; behaviour, social and emotional development } \\
\text { and management (including motivation); development of basic skills (reading and } \\
\text { numeracy) in adulthood; systemic interventions and strategic planning in FE and } \\
\text { post-16 services. }\end{array}$ \\
\hline
\end{tabular}

\section{Section 5 - DEVELOPMENT}

5.1a $\quad$ Demonstrates knowledge of theories of adult learning.

5.1b Recognises circumstances or behaviours which may potentially challenging for young people aged 16-25 (including parenthood, development of sexuality, drug and alcohol use, chronic ill health) and which can increase vulnerability.

5.1c Demonstrates knowledge of how to assess risk and resilience in relation to changing life circumstances.

5.2a Demonstrates awareness of the effects of oppression and discrimination on young people and their families.

5.2b Recognises ethical or safeguarding issues, knows how to address these appropriately and when to seek supervision.

5.2c Recognises and discusses limits of own professional and legal knowledge.

5.3 Other areas to be addressed via an extension to existing curricula: developing independence; neuropsychological development; social and emotional development; vocational skills 


\section{Section 6 - TRANSITIONS}

\begin{tabular}{|l|l|}
\hline $6.1 \mathrm{a}$ & $\begin{array}{l}\text { Understands issues with might arise within the context of young people aged 16-25 } \\
\text { making transitions between educational and/or vocational institutions, or into } \\
\text { employment. } \\
\text { 6.1b }\end{array}$ \\
\hline $6.2 \mathrm{a}$ & $\begin{array}{l}\text { Understands issues which might arise as a result of other life transitions (e.g. to } \\
\text { independent living; parenthood; adulthood). }\end{array}$ \\
\hline $6.2 \mathrm{~b}$ & $\begin{array}{l}\text { Works collaboratively with others to support transitions made by young people aged } \\
\text { Within multidisciplinary settings can work with other professionals to incorporate } \\
\text { psychological knowledge into transition planning and monitoring. }\end{array}$ \\
\hline 6.3 & $\begin{array}{l}\text { Other areas to be addressed via an extension to existing curricula: professional roles } \\
\text { and responsibilities. }\end{array}$ \\
\hline
\end{tabular}

Figure 1: Competency framework for TEPs working with young people aged 16-25

\section{Discussion}

The discussion will touch briefly on the some of the outcomes, as presented within the competency framework, before moving on to explore implications of developing competencies in working with young people aged 16-25 more generally. Fallon et al. (2010) identified the usefulness of a core initial training curriculum in helping EPs to be clear about their professional identity and it is hoped that the provision of a curriculum framework which could be widely adopted by training programmes will help add clarity to the role of TEPs in working with young people aged 16-25.

To begin with, understanding of the post-16 context incorporates not only knowledge of post-compulsory educational provision, but illustrates the need for EPs to be aware of the socio-political context in which they practice. Highlighted within the competency framework is the need for effective professional collaboration, particularly with colleagues whose role is specific to working with post-16 learners. Hellier (2009) notes that for Scottish PSPS, working collaboratively with multiagency partners provided new challenges, including understanding the role of new partners and seeking to facilitate positive connections between new and existing ones. Knowledge about the Local Offer, which requires local 
authorities to publish centrally information about education, health and social care services for children with SEN (DfE, 2014) will provided additional challenges for EPs who may previously have been unfamiliar of provision and resources offered by FE colleges and other post 16 settings. EPS will need to be familiar with the curricula, courses, programmes and pathways offered by educational establishments and training providers and the support that they have in place for supporting young people with SEN (DfE, 2014).

The Mental Capacity Act (2005) has significant implications for EPs, not only in terms of understanding legislation, but in understanding the principles of consent and shared decision making. Harding (2009) highlights some of the complexities for EPs in harnessing the views of young people with PMLD including how time and skills are required to elicit information, ethical issues (including consent, assent, confidentiality and ownership) and conceptual issues, relating to whether people with severe and profound and multiple learning difficulties (PMLD) can be said to have views. Harding (2009) proposes that EPs are well placed to be involved in eliciting the views of young people with PMLD and offers guidance as to how EPs might work at a number of levels to support this. In terms of supporting assessment of mental capacity British Psychological Society (BPS) (2010) guidance might offer a useful framework for supporting practice.

Assessment of 16-25 learners in different contexts potentially provides additional challenges for EPs which highlight the differences in support and access criteria between child and adult services (Cerebra, 2014). For instance Pavey, Meehan and Waugh (2010) highlight that post-16 assessment for dyslexia tends to be based on the discrepancy model which for the majority of EPs would have been discredited by the BPS Division of Educational and Child Psychology (DECP), 1999) Working Group Report. Interestingly, dyslexia assessment in young people aged 16-25 is the focus of a current DECP working group and findings will be influential in supporting the work of EPs undertaking assessment in FE and HE settings. EPs also need to be aware of the additional responsibilities surrounding assessment in FE and $\mathrm{HE}$ contexts. For example, recent SpLD Assessment Standards Committee (SASC) guidance in relation to Attention Deficit Hyperactivity Disorder (ADHD) states that: 
...practitioner psychologists and specialist teacher assessors who have relevant training can identify specific learning difficulties and patterns of behaviour that together would strongly suggest a student has ADHD; and in this situation they can make relevant recommendations for support at Further and or Higher Education institutions (SASC, 2013).

It is likely that many EPs may feel uneasy with the type of diagnostic role described above and as such there are potential ethical and professional issues for EPs working within these sectors. Greater alignment of assessment protocols across the $0-25$ age range, in accordance with evidence-based best practice is a potential contribution EPs can make in improving links between child and adult services, consequently enabling more coherent pathways into accessing services and resources in adulthood.

There was agreement at the final expert group meeting that person-centred planning techniques were an important component of working with young people aged 16-25, particularly in light of the five elements identified as improving life chances for young people with SEN identified by Preparing for Adulthood (2013). Craig (2009) highlights a number of benefits to person-centred planning including consulting with the young person, focusing on positives, having little or no literacy requirements and facilitating shared understandings and a sense of what is important to the young person. Preparing for Adulthood (2013) advocates the use of person-centred planning in offering a personalised approach to planning and with it, more control and choice for young people with SEN.

Young people experience different life challenges which can increase vulnerability, including parenthood, development of sexuality, drug and alcohol use and chronic ill health. EPs need to be mindful of theories of adolescence and early adulthood (Hayton, 2009) as well as the need to develop new partnerships with adult service providers (MacKay \& Hellier, 2009). Finally, practice within the area of transitions suggests an already developing pool of small scale research (Bradley, 2012; Craig, 2009; Mallinson, 2009) which will be useful in informing the development of practice amongst EPs. Furthermore, Knox (2011) advocates the application of psychological theory, including developmental psychology and the psychology of change in supporting young people and proposes a further role for EPs in supporting local 
authority practice and policy making around transitions. Hellier (2009) notes that in Scotland, the historic view that school leavers are the responsibility of others has been challenged through PSPS events and through building specific PSPS training and practice into initial EP training.

Clifford (2013) suggests that EPs need to recognise the skills and knowledge they already have and to ascertain which are transferrable in supporting young people aged 16-25, alongside identifying areas for development. What is clear from this research is that in developing a competency framework, while there are specific areas which need addressing, a significant proportion of the necessary knowledge can be developed through extending to current training curricula delivered on initial doctoral training programmes. Furthermore, the process skills identified within this competency framework are not distinct to post 16 learners and are skills which have been integral to training programmes and are reflected in the standards of proficiency (Health and Care Professions Council (HCPC), 2009).

In relation to this research, there are some limitations of the Delphi technique which should be noted. While Powell (2003) recognises the method as a "way of harnessing collective wisdom" she usefully cautions that the findings of a Delphi "represent expert opinion rather than indisputable fact" (p. 381). Furthermore, Keeney, Hasson and Mckenna (2001) note that knowledge of a particular topic does not necessarily imply expertise. As the research sample was self-selecting; and working with young people aged $16-25$ is a broad area (within which EPs might have expertise in particular sub-fields) this is perhaps a valid criticism within this study. Providing more specific criteria in relation to a definition of 'expertise' may have been an enhancement of the research design.

There have also been criticisms about the reliability of Delphi (cf (Wiliams \& Webb, 1994). It is interesting in this instance to speculate whether consultation with a different panel of experts would have derived the same curriculum. However, given that volunteers were recruited via EPNET, it could be argued that this offered an opportunity for most UK EPS with relevant knowledge to contribute. Given the ongoing developments in post-school 
practice amongst UK EPs, it should be considered that were the study to be repeated in a few years' time, outcomes may be different, as more EPs become involved in developing and shaping practice within their own local contexts.

The introduction of post-16 work represents a whole new sector of EP work in a context in which changes have arisen over a very short space of time (Hellier, 2009). The democratic principles underlying the Delphi process have enabled us to harness the consensus views of EPs with expertise in the field to develop a competency framework which it is hoped will provide a useful starting for in relation to the identification of existing skills. Furthermore, the development of professional objectives incorporating content and process related knowledge and skills potentially offers practice placement supervisors a clear protocol for making decisions about competence and identifying future training needs. Finally, it is hoped that the usefulness of this framework may extend beyond the realms of initial training and could be used by EPSs beginning to discuss and address issues such as service organisation and delivery, capacity, training and supervision and to allow practitioner EPs to make informed choices about continuing professional development priorities.

\section{References}

Arnold, C., \& Baker, T. (2012). Transitions from school to work: Applying psychology to "NEET". Educational and Child Psychology, 29(3), 67-80.

Bradley, J. (2012). Young people navigating the transition to university: Policy, context and influences. Educational and Child Psychology, 29(1), 101-110.

British Psychological Society. (2010). Audit Tool for Mental Capacity Assessments. . British Psychological Society: Leicester. Retrieved from http://www.bps.org.uk/sites/default/files/documents/audit-tool-mental-

Carter, S., Cameron, F., Houghton, J., \& Walton, M. (2013). Never mind what I like, it's who I am that matters: an investigation into social pedagogy as a method to enhance the involvement of young people with learning disabilities. British Journal of Learning Disabilities, 41(4), 312-319. doi:10.1111/bld.12002

Cerebra. (2014). Transition To Adulthood: A Guide For Parents. Retrieved June 11, 2014, from http://www.cerebra.org.uk/English/getinformation/guides for parents/Pages/TransitionGuideToAdulthoodAGuideForParents.aspx 
Clifford, V. (2013). Applying Psychology to Education and Learning for 16 to 25 year olds New horizons, opportunities and challenges 2013. Training session presented to Bolton EPS, 19 December.

Craig, L. (2009). Post-school transitions: Exploring practice in one local authority. Educational and Child Psychology, 26(1), 41-51.

Currie, R., \& Goodall, L. (2009). Using collaborative action research to identify and support young people at risk of becoming NEET. Educational and Child Psychology, 26(1), 6775.

Dalkey, N. C. (1969). The Delphi Method: An Experimental Study on Group Opinion. Santa Monica: The RAND Corporation. Retrieved from http://www.rand.org/content/dam/rand/pubs/research_memoranda/RM5888/RM588 8.pdf

DfE. (2014). Special educational needs and disability code of practice: 0 to 25 years. London: DfE.

Division of Educational and Child Psychology. (1999). Dyslexia, Literacy and Psychological Assessment. Leicester: BPS.

Evans, S. P., Grahamslaw, L., Henson, L., \& Prince, E. (2012). Is the restructured initial professional training in educational psychology fit for purpose? Educational Psychology in Practice, 28(4), 373-393. doi:10.1080/02667363.2012.725976

Fallon, K., Woods, K., \& Rooney, S. (2010). A discussion of the developing role of educational psychologists within Children's Services. Educational Psychology in Practice, 26(1), 123. doi:10.1080/02667360903522744

Fouad, N. A., Grus, C. L., Hatcher, R. L., Kaslow, N. J., Hutchings, P. S., Madson, M. B., ... Crossman, R. E. (2009). Competency benchmarks: A model for understanding and measuring competence in professional psychology across training levels. Training and Education in Professional Psychology, 3(4, Suppl), S5-S26. doi:10.1037/a0015832

Hammond, N. (2013). Introducing Forum Theatre to elicit and advocate children's views. Educational Psychology in Practice, 29(1), 1-18. doi:10.1080/02667363.2012.733309

Harding, E. (2009). Obtaining the views of children with profound and multiple learning difficulties . Educational and Child Psychology, 26(4), 117-128.

Hasson, F., Keeney, S., \& McKenna, H. (2000). Research guidelines for the Delphi survey technique. Journal of Advanced Nursing, 32(4), 1008-15. Retrieved from http://www.ncbi.nlm.nih.gov/pubmed/11095242

Hayton, R. (2009). Young people growing up in rural communities: Opportunities for educational psychologists to work with emerging adults. Educational and Child Psychology, 26(1), 60-67. 
HCPC. (2009). Standards of proficiency: Practitioner psychologists. London: HCPC.

Hellier, C. (2009). Developing Post-School Psychological Services in Scotland: Fit for Purpose? . Educational and Child Psychology, 26(1), 22-32.

Ingram, R. (2013). Interpretation of children's views by educational psychologists: dilemmas and solutions. Educational Psychology in Practice, 29(4), 335-346.

doi:10.1080/02667363.2013.841127

Jane, E. C. (2010). Psychology for engaging vulnerable young people: the role of the community educational psychologist in supporting professionals who work with young people. University of Exeter: Unpublished Doctoral Thesis.

Kaslow, N. J., Borden, K. A., Collins, F. L., Forrest, L., Illfelder-Kaye, J., Nelson, P. D., ... Willmuth, M. E. (2004). Competencies conference: future directions in education and credentialing in professional psychology. Journal of Clinical Psychology, 60(7), 699-712. doi:10.1002/jclp.20016

Keeney, S., Hasson, F., \& Mckenna, H. P. (2001). A critical review of the Delphi technique as a research methodology for nursing. International Jurnal of Nursing Studies, 38, 195200.

Knox, L. O. (2011). Special educational needs: from education to employment - exploring perceptions of successful transition. University of East London: Unpublished Doctoral Thesis.

Linstone, H. A., \& Turoff, M. (2002). The Delphi Method - Techniques and applications. (H. A. Linstone \& M. Turoff, Eds.)The delphi method - Techniques and applications (pp. 1616). UNIDO. doi:10.2307/1268751

MacKay, T. (2009). Post-School Services: International perspectives on a distinctly Scottish development. Educational and Child Psychology, 26(1), 8-21.

MacKay, T., \& Hellier, C. (2009). Editorial. Educational and Child Psychology, 26(1), 5-8.

Mallinson, A. (2009). From school to further education: Student and teacher views of transition, support and drop-out. Educational and Child Psychology, 26(1), 33-40.

Miller, G. E. (1990). The assessment of clinical skills/competence/performance. Academic Medicine : Journal of the Association of American Medical Colleges, 65(9 Suppl), S63S67. doi:10.1097/00001888-199009000-00045

National Association of School Psychologists. (2010). Standards for Graduate Preparation of School Psychologists (pp. 1-16). Bethsda, MD: National Association of School Psychologists.

OSPA Project. (2013). OSPA Project: Objective Structured Professional Assessments. A collaboration between University College London, Southampton University and 
Manchester University. Retrieved July 30, 2014, from http://www.ucl.ac.uk/ospaproject/

Pavey, B., Meehan, M., \& Waugh, A. (2010). Dyslexia-Friendly Further and Higher Education. London: Sage.

Powell, C. (2003). The Delphi technique: myths and realities. Journal of Advanced Nursing, 41(4), 376-82. Retrieved from http://www.ncbi.nlm.nih.gov/pubmed/12581103

Preparing for Adulthood. (2013). Delivering support and aspiration for disabled young people. Bath: Preparing for Adulthood Programme.

Robinson, K. (2010). A study of young lesbian and gay people's school experiences. Educational Psychology in Practice, 26(4), 331-351. doi:10.1080/02667363.2010.521308

Rodolfa, E., Bent, R., Eisman, E., Nelson, P., Rehm, L., \& Ritchie, P. (2005). A Cube Model for Competency Development: Implications for Psychology Educators and Regulators. Professional Psychology: Research and Practice. doi:10.1037/0735-7028.36.4.347

Scottish Executive. (1999). Implementing effectiveness: Raising potential. The Beattie Committee Report. . Edinburgh.

Shogren, K. A., Wehmeyer, M. L., Palmer, S. B., Rifenbark, G. G., \& Little, T. D. (2013). Relationships Between Self-Determination and Postschool Outcomes for Youth With Disabilities. The Journal of Special Education, (June 2013).

doi:10.1177/0022466913489733

SpLD Assessment Standards Committee. (2013). ADHD Guidance - September 2013. Retrieved May 23, 2014, from http://www.sasc.org.uk/SASCDocuments/ADHD Guidance-September 2013.pdf

TSO (The Stationery Office). (2005). Mental Capacity Act 2005: Code of Practice. Norwich. Retrieved from http://www.justice.gov.uk/downloads/protecting-thevulnerable/mca/mca-code-practice-0509.pdf

Wiliams, P. L., \& Webb, C. (1994). The Delphi technique : a methodological discussion. Journal of Advanced Nursing, 19, 180-186. 